\title{
The endoscopic transoral approach to the craniovertebral junction: an anatomical study with a clinical example
}

\author{
Andrew K. Chan, MD, ${ }^{1}$ Arnau Benet, MD, ${ }^{1,2}$ Junichi Ohya, MD, ${ }^{1}$ Xin Zhang, MD, PhD, ${ }^{1}$ \\ Todd D. Vogel, MD, ${ }^{1}$ Daniel W. Flis, MD, ${ }^{2}$ Ivan H. El-Sayed, MD, ${ }^{2}$ and Praveen V. Mummaneni, MD ${ }^{1}$ \\ Departments of ${ }^{1}$ Neurological Surgery and ${ }^{2}$ Otolaryngology, University of California, San Francisco, California
}

\begin{abstract}
OBJECTIVE The microscopic transoral, endoscopic transnasal, and endoscopic transoral approaches are used alone and in combination for a variety of craniovertebral junction (CVJ) pathologies. The endoscopic transoral approach provides a more direct exposure that is not restricted by the nasal cavity, pterygoid plates, and palate while sparing the potential morbidities associated with extensive soft-tissue dissection, palatal splitting, or mandibulotomy. Concerns regarding the extent of visualization afforded by the endoscopic transoral approach may be limiting its widespread adoption.

METHODS A dissection of 10 cadaver heads was undertaken. CT-based imaging guidance was used to measure the working corridor of the endoscopic transoral approach. Measurements were made relative to the palatal line. The built-in linear measurement tool was used to measure the superior and inferior extents of view. The superolateral extent was measured relative to the midline, as defined by the nasal process of the maxilla. The height of the clivus, odontoid tip, and superior aspect of the C-1 arch were also measured relative to the palatal line. A correlated clinical case is presented with video.
\end{abstract}

RESULTS The CVJ was accessible in all cases. The superior extent of the approach was a mean $19.08 \mathrm{~mm}$ above the palatal line (range 11.1-27.7 mm). The superolateral extent relative to the midline was $15.45 \mathrm{~mm}$ on the right side (range 9.6-23.7 mm) and $16.70 \mathrm{~mm}$ on the left side (range 8.1-26.7 mm). The inferior extent was a mean $34.58 \mathrm{~mm}$ below the palatal line (range 22.2-41.6 mm). The mean distances were as follows: palatal line relative to the odontoid tip, $0.97 \mathrm{~mm}$ (range -4.9 to $3.7 \mathrm{~mm}$ ); palatal line relative to the height of the clivus, $4.88 \mathrm{~mm}$ (range -1.5 to $7.3 \mathrm{~mm}$ ); and palatal line relative to the C-1 arch, $-2.75 \mathrm{~mm}$ (range -5.8 to $0 \mathrm{~mm}$ ).

CONCLUSIONS The endoscopic transoral approach can reliably access the CVJ. This approach avoids the dissections and morbidities associated with a palate-splitting technique (velopharyngeal insufficiency) and the expanded endonasal approach (mucus crusting, sinusitis, and potential lacerum or cavernous-paraclival internal carotid artery injury). For appropriately selected lesions near the palatal line, the endoscopic transoral approach appears to be the preferred approach.

http://thejns.org/doi/abs/10.3171/2015.11.FOCUS15498

KEY WORDS endoscopic transoral; endoscopy; craniovertebral junction; endo-oral; surgical anatomy

$\mathrm{T}$ HE microscopic transoral, endoscopic transnasal, and endoscopic transoral approaches are used alone and in combination for a variety of craniovertebral junction (CVJ) pathologies. For several decades, the transoral approach has been used to access the CVJ. . $^{1,5,7,8,15,18,26,28-31,38}$ However, the approach often necessitates dissection of the soft tissue (e.g., maxillotomy, palatal split, mandibulotomy) and is known to be associated with velopharyngeal insufficiency, dysphagia, and dysphonia. ${ }^{7,21,35,40}$
The endonasal approach to the $\mathrm{CVJ}^{4,6,13,14,19,20,22,24,25,27,32 \text {, }}$ $33,37,42-44$ obviates the need for palatal splitting and an oral retractor system. This is believed to decrease velopharyngeal insufficiency and postoperative tongue and oral swelling associated with postoperative tracheostomy and gastrostomy. Indeed, endoscopic approaches through the nasal cavity are linked to shorter hospital lengths of stay and decreased latency to tolerating oral intake in comparison with the standard transoral approach..$^{16,23,35}$ However, 
the inferior view is limited by the palate ${ }^{37}$ and the endonasal approach is linked to mucus crusting ${ }^{10}$ and sinusitis. ${ }^{39}$ In addition, the lacerum and paraclival (cavernous) segments of the internal carotid artery, as well as the hypoglossal nerves, serve as the lateral boundaries for the endonasal approach to the clivus and the CVJ, posing an additional risk when utilizing this corridor. Also, transient velopharyngeal incompetence, tracheostomy, and gastrostomy ${ }^{32}$ have been described for the endonasal approach to the CVJ, though this study was early in the evolution of approach.

Alternatively, an endoscopic transoral approach to de-

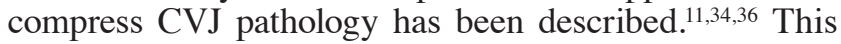
approach avoids the destruction of the nasal cavity and postoperative crusting of the endonasal approach, while affording a surgical corridor that can reach below the palatal line. The ideal surgical approach for lesions affecting the CVJ remains unclear and is left to surgeon preference.

In contrast to the transnasal approach, the endoscopic transoral approach involves a shorter working distance to the CVJ. The transoral endoscopic approach is not restricted by the nasal cavity, pterygoid plates, and palate (which are associated with the endonasal approach) while sparing the potential morbidity associated with extensive softtissue dissection (which is associated with the endonasal approach) or palatal splitting and mandibulotomy (which are associated with the microscopic transoral approach). Additionally, the endoscopic transoral approach has been shown to have a significantly larger working corridor than that afforded by the microscopic transoral approach. ${ }^{34}$ Still, there are concerns regarding the extent of visualization afforded by the endoscopic transoral approach that may be limiting its widespread adoption: namely, the maximum extent of superior reach is unknown.

Thus, quantification of the approach afforded by the endoscopic transoral approach may identify the range of its applicability for CVJ pathology. In the present study, we measure the surgical corridor of the endoscopic transoral approach in cadaveric specimens and provide an example clinical case with video to demonstrate utilization of the procedure for appropriately selected CVJ pathology.

\section{Methods}

To assess the working corridor provided by the endoscopic transoral approach, we first carried out an anatomical study to measure the working corridor of the endoscopic transoral approach using CT-based image guidance in cadaveric specimens, followed by a surgical simulation to visualize the relevant anatomical landmarks. We also provide a video presentation of a clinical case to demonstrate the technique.

\section{Cadaveric Assessment}

Ten human heads were prepared for surgical simulation using our neurosurgical embalming method. ${ }^{2}$ A highresolution CT scan was obtained of each cadaveric head. These images were uploaded into a neuronavigation system (NAV3i Navigation Platform, Stryker).

We registered each head for neuronavigation by using a facial mask or fiducials. After checking for accuracy, we referenced the neuronavigation tools. Anatomical landmarks were defined, and the anatomy reached by a straight neuronavigation wand was measured.

The endoscope was introduced into the oral cavity after retracting the mouth wide open and depressing the tongue. After exploring the oropharynx, the uvula was gently pushed superiorly. Next, the endoscope was introduced into the nasal cavity, and the uvula was identified. A 3-0 silk stitch was passed to the base of the uvula and used to pull the uvula superiorly and retract the soft palate. Subsequently, the endoscope was passed through the oral cavity, and the upper oropharynx and lower nasopharynx were inspected. The navigation probe was introduced into the field, and measurements were obtained from the navigation software. The soft tissue was not divided.

Measurements were made relative to the palatal line. The palatal line is a line drawn along the floor of the nasal cavity, extending from the premaxilla parallel to the hard palate at the CVJ (Fig. 1A). ${ }^{12}$ The built-in linear measurement tool was used to measure the superior and inferior extents of view in the midline sagittal plane. Figure 1A and $\mathrm{B}$ demonstrates the planes used for both the superior and inferior measurements. The superolateral extent was measured relative to the midline, as defined by the nasal process of the maxilla. Figure $1 \mathrm{C}$ demonstrates the plane used for superolateral measurement. The height of the clivus, odontoid tip, and superior aspect of the C- 1 arch were also measured relative to the palatal line. The measurements are presented in millimeters \pm 1 standard deviation.

In 1 specimen, a complete endoscopic endonasal transclival approach was first performed, preserving the CVJ and atlas. The endoscopic transoral approach was then performed to visually compare the final intradural and spinal exposures (Fig. 1D).

After the variables were measured, all data were compiled onto a spreadsheet. MATLAB (MathWorks) was used for the descriptive statistical analyses.

\section{Clinical Case}

We present the case of a patient with a C1-2 retrodental pannus causing ventral spinal cord compression who underwent an endoscopic transoral approach for CVJ decompression. Endoscopic navigation was performed using a $0^{\circ}$ rigid endoscope (high-definition 1488 camera, Stryker Endoscopy). A video is provided (Video 1).

VIDEO 1. Video depicting the endoscopic transoral odontoidectomy. Copyright Andrew K. Chan. Published with permission. Click here to view.

\section{Results}

A primary concern involving the endoscopic transoral approach is its superior extent of reach into the posterior pharynx. In our cadaveric specimens, the mean superior reach of the navigation probe using the endoscopic transoral route was $19.1 \pm 6.0 \mathrm{~mm}$ above the palate line (range $11.1-27.7 \mathrm{~mm})$.

The mean inferior reach of the probe using the endoscope was $34.6 \pm 7.8 \mathrm{~mm}$ below the palatal line (range 22.2-46.4 mm). The superolateral reach of the approach was $15.5 \pm 4.5 \mathrm{~mm}$ to the right of the midline (range 9.6- 


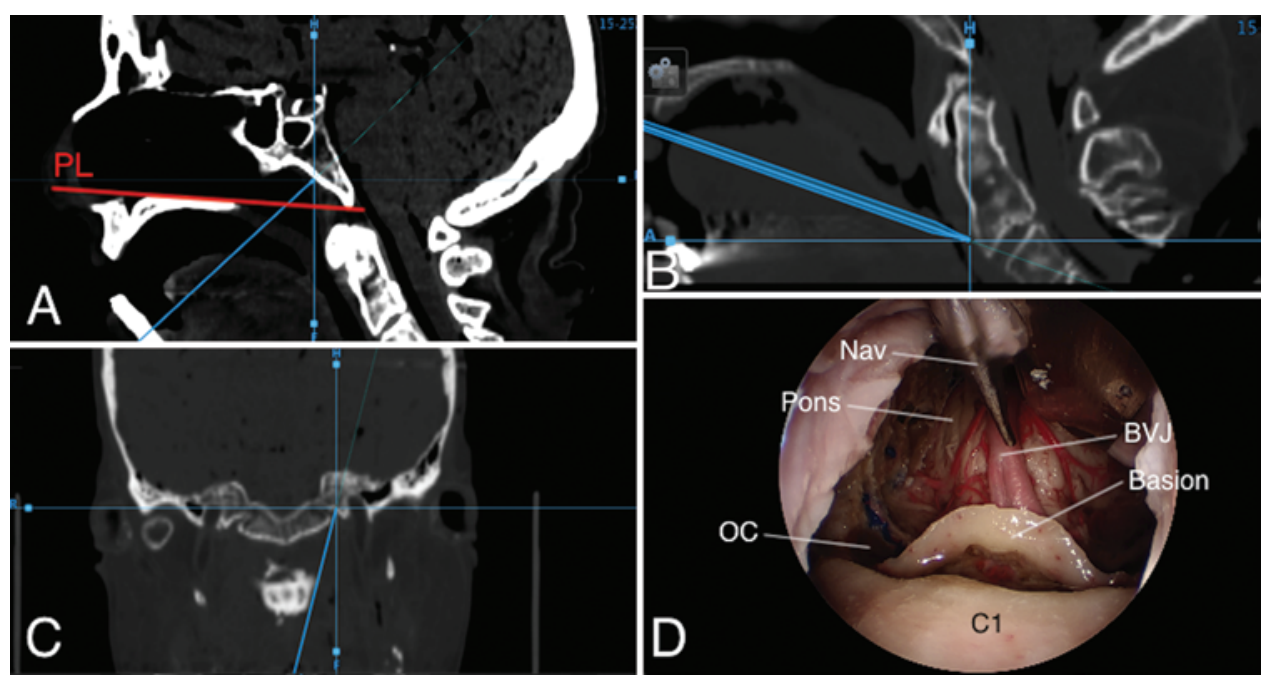

FIG. 1. A-C: CT-based image guidance was used to obtain quantitative measurements of the superior extent (A), inferior extent $(B)$, and superolateral extent of the working corridor in the endoscopic transoral approach (C). D: In this specimen, the complete endoscopic endonasal transclival approach was performed, preserving the CVJ and atlas. The endoscopic transoral approach was then performed to visually compare the final intradural and spinal exposures. The trajectory of the neuronavigation probe demonstrates the superior extent of the endoscopic transoral corridor in this specimen. BVJ = basilar-vertebral artery junction; $\mathrm{C} 1$ = anterior tubercle of the $\mathrm{C}-1$ arch; Nav = navigation probe; $\mathrm{OC}=$ occipital condyles; $\mathrm{PL}=$ palatal line.

$23.7 \mathrm{~mm}$ ) and $16.7 \pm 5.8 \mathrm{~mm}$ to the left of the midline (range 8.1-26.7 mm). We referenced the neuronavigation tool to simulate an endoscope. The neuronavigation tool was able to reach the CVJ in all specimens $(\mathrm{n}=10 ; 100 \%)$. The trajectory allowed adequate exposure for simulated odontoidectomy.

The measurements obtained between the palatal line and the odontoid process, clivus, and the superior aspect of the $\mathrm{C}-1$ arch are presented in Table 1.

\section{Clinical Case}

History and Examination

The patient is a 58-year-old woman with a large retrodental pannus causing cervical stenosis and myelopathy (Fig. 2A). She initially presented with gait difficulty and right upper-extremity numbness. For these symptoms, she had previously undergone a C1-6 laminectomy and posterior fusion 6 months earlier (Fig. 2B). A postoperative MR image revealed interval growth in her C-2 pannus (Fig. 2C and D). An endoscopic transoral odontoidectomy was performed for decompression and pathological diagnosis because of a concern for a malignant and infectious etiology.

\section{Operation}

An endoscopic transoral approach was used to decompress the patient's CVJ. The endotracheal tube was placed

TABLE 1. Anatomical relationship of the CVJ relative to the palatal line

\begin{tabular}{lcl}
\hline \multicolumn{1}{c}{ Structure } & Mean (SD) & \multicolumn{1}{c}{ Range } \\
\hline Odontoid tip, mm & $1.0(2.8)$ & -4.9 to 3.7 \\
\hline Superior aspect of C-1 arch, $\mathrm{mm}$ & $-2.8(2.0)$ & -5.8 to 0 \\
\hline Clival height, $\mathrm{mm}$ & $4.9(2.6)$ & -1.5 to 8.5 \\
\hline
\end{tabular}

in the midline of the mouth. The patient was positioned supine, and her head was pinned in a Mayfield headholder. The patient was positioned so that her feet were toward the anesthesiologist. The surgeon stood to the left of the patient, while the assistant holding the endoscope stood to the right of the patient. The scrub nurse stood to the left

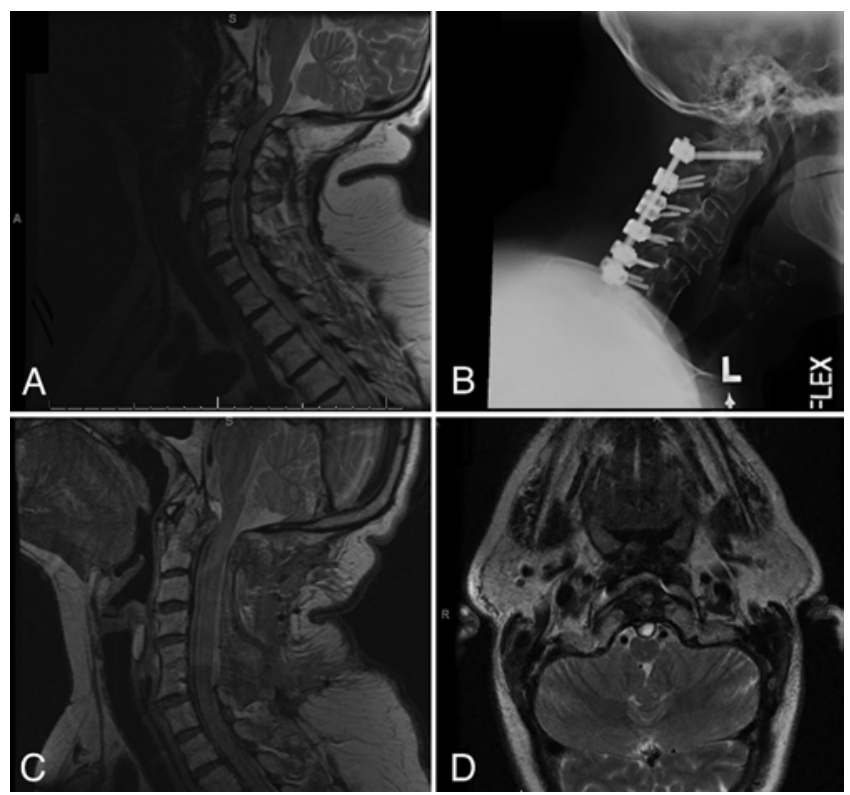

FIG. 2. A: Sagittal T2-weighted MR image revealing a retrodental pannus with severe stenosis from $\mathrm{C}-1$ to $\mathrm{C}-5$ and cord contusion at C-1. B: Lateral plain cervical radiograph obtained after C1-2 laminoforaminotomies, C2-6 laminectomies and foraminotomies, and C1-6 posterior spinal instrumented fusion. C and D: Sagittal (C) and axial (D) T2-weighted MR images revealing interval growth in the prominent retrodental pannus, measuring $8 \times 9 \times 22 \mathrm{~mm}$, resulting in cervicomedullary compression. 
of the patient. Figure 3 demonstrates the operating room setup for the endoscopic transoral approach. ${ }^{31}$

Clindamycin $(600 \mathrm{mg})$ was administered, and dexamethasone was given to decrease airway edema. Somatosensory and motor evoked potentials were used, and preoperative baseline studies were obtained. As the patient already underwent $\mathrm{C} 1-6$ instrumented posterior spinal fusion, cranial traction was not placed. The mouth and face were prepared and draped. Brainlab neuronavigation was registered. A Spetzler-Sonntag oral retractor system was used to open the patient's jaw, with care taken to place the tongue underneath the tongue blade of the retractor while avoiding trapping the tongue against the teeth (Fig. 4). The oral cavity was injected with $1 \mathrm{ml}$ of $1 \%$ lidocaine in each greater palatine foramen. Anesthesia aided a wide mandibular opening by creating a temporary neuromuscular blockade.

The endoscope was used for the remainder of the case (Video 1).

To maximize the exposure afforded by the endoscopic transoral approach while avoiding splitting of the palate,

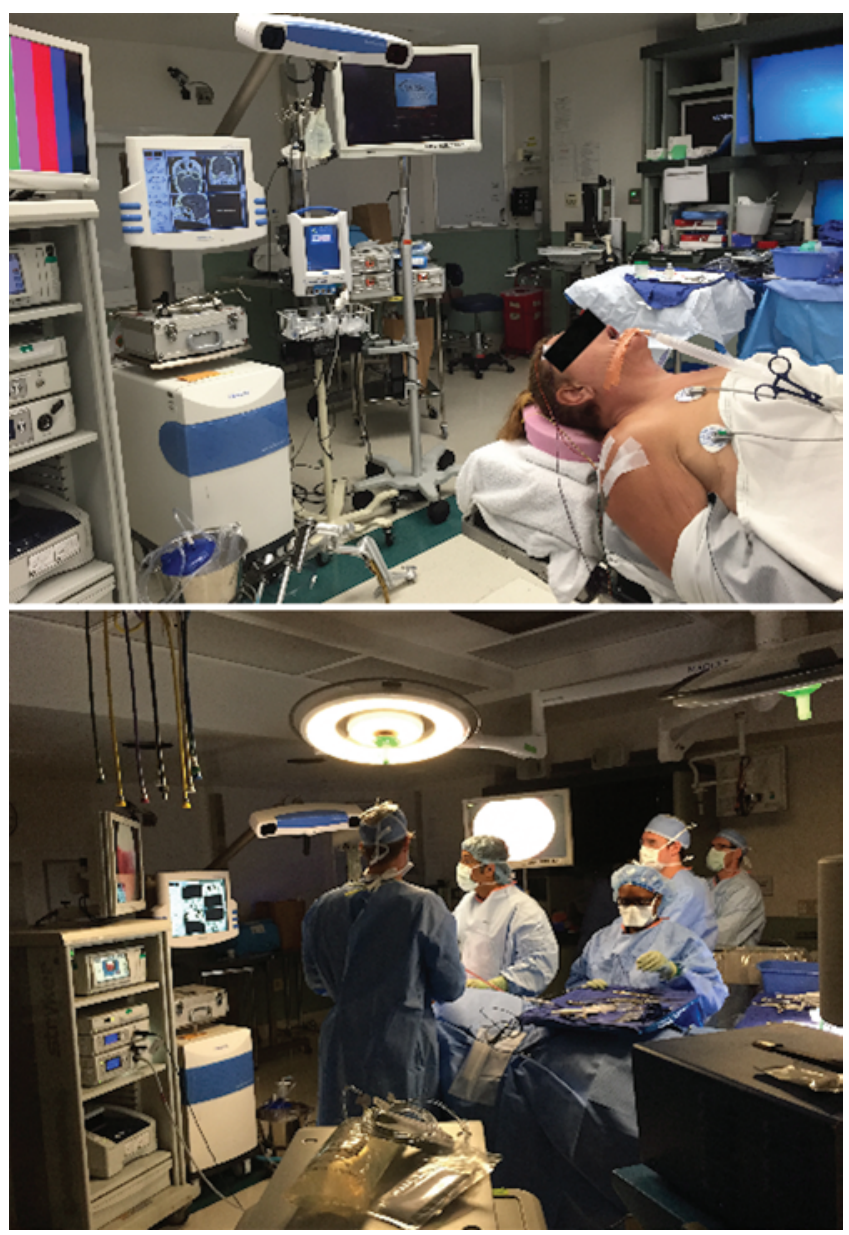

FIG. 3. Upper: Operating room setup. The patient is positioned with the surgeon to the left of the patient's head, which is optimized for the righthanded surgeon. Lower: The assistant with an endoscope is positioned on the opposite side of the patient's head. The scrub nurse is positioned to the left of the patient on the same side as the surgeon. The neuronavigation system and endoscope's monitor tower is located in clear view behind the patient's head.

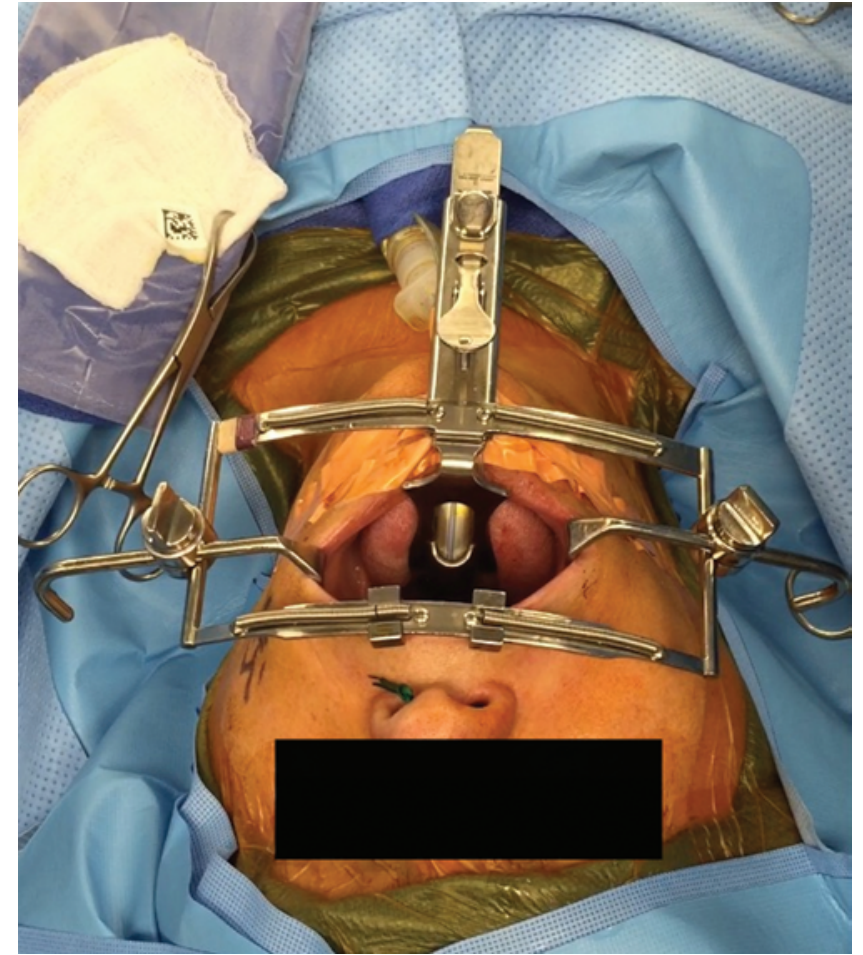

FIG. 4. The Spetzler-Sonntag retractor is placed carefully to ensure that the tongue and endotracheal tube are retracted inferiorly without trapping the tongue against the teeth.

we placed a 0 silk suture into the uvula and pulled this suture up through the nostril to elevate the soft palate for the duration of the procedure (Fig. 5A and B). The Spetzler-Sonntag retractor was then reapplied, ensuring that the uvula was retracted superiorly. This is a key element of the procedure, as the upper portion of the posterior pharynx is visualized without disruption of the soft and/or hard palate. This is beneficial for several reasons: this prevents secretions from running into the future incision and avoids morbidity, such as dysphonia or nasopharyngeal insufficiency, associated with soft-palate dissection. The retractor, in conjunction with the elevation of the uvula, provides a large exposure of the posterior pharyngeal area (Fig. 5C).

After injection of the posterior pharynx with $1 \%$ lidocaine with epinephrine, neuronavigation was used to identify the area of the posterior pharyngeal wall overlying the odontoid process and C-1 arch.

Under endoscopic visualization, a 2-cm incision was made overlying the midline $\mathrm{C}-1$ arch. Care was taken to minimize the extent of the incision, taking into account that the incision would be further expanded by subsequent retraction. This incision was taken through the posterosuperior pharyngeal constrictor muscle in the midline.

A Crockard self-retaining retractor was placed (Fig. 5D). Once the retractor was placed, care was taken throughout the remainder of the procedure to avoid making contact with the oral cavity aside from the incision.

The soft tissue of the posterior pharynx was dissected to isolate the $\mathrm{C}-1$ arch using monopolar electrocautery and a subperiosteal technique. Isolation and skeletonization of 

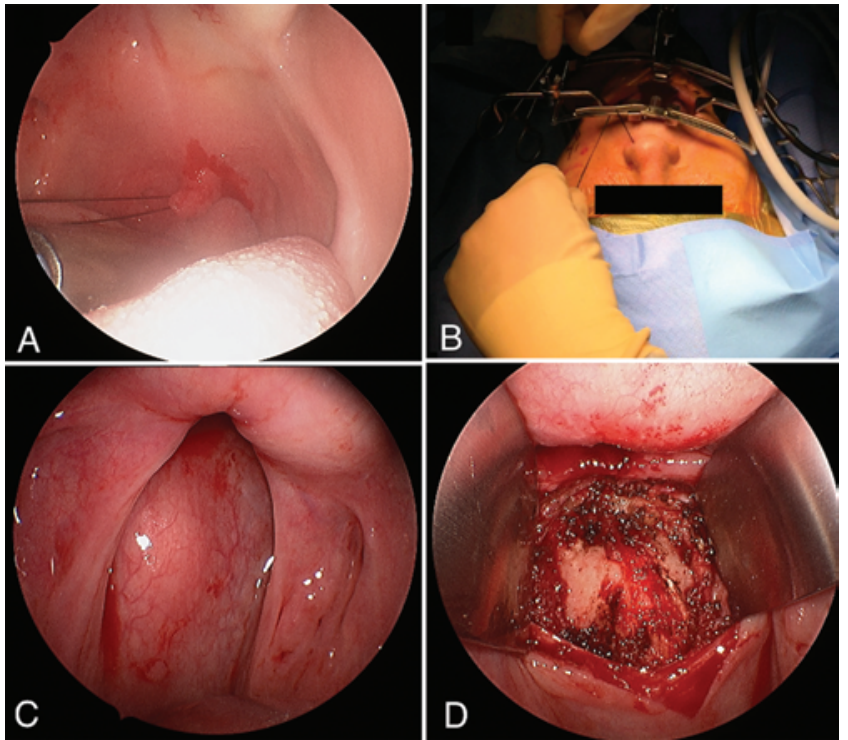

FIG. 5. A and B: A suture is placed through the uvula, retracted through the nares $(A)$, and is attached to the Spetzler-Sonntag retractor to provide elevation of the uvula and soft palate (B). C and D: Elevation of the uvula and soft palate allows for a significantly wider surgical corridor while avoiding soft-tissue dissection (C). A pharyngeal incision is made over the anterior arch of $\mathrm{C}-1$, and a Crockard retractor is placed to spread the incision laterally (D).

the $\mathrm{C}-1$ arch was confirmed with neuronavigation (Fig. $6 \mathrm{~A})$.

A drill was used to remove the anterior arch of $\mathrm{C}-1$ (Fig. 6B). Using the endoscope, gross visualization of the patient's prior C-1 lateral mass screws marked the lateral
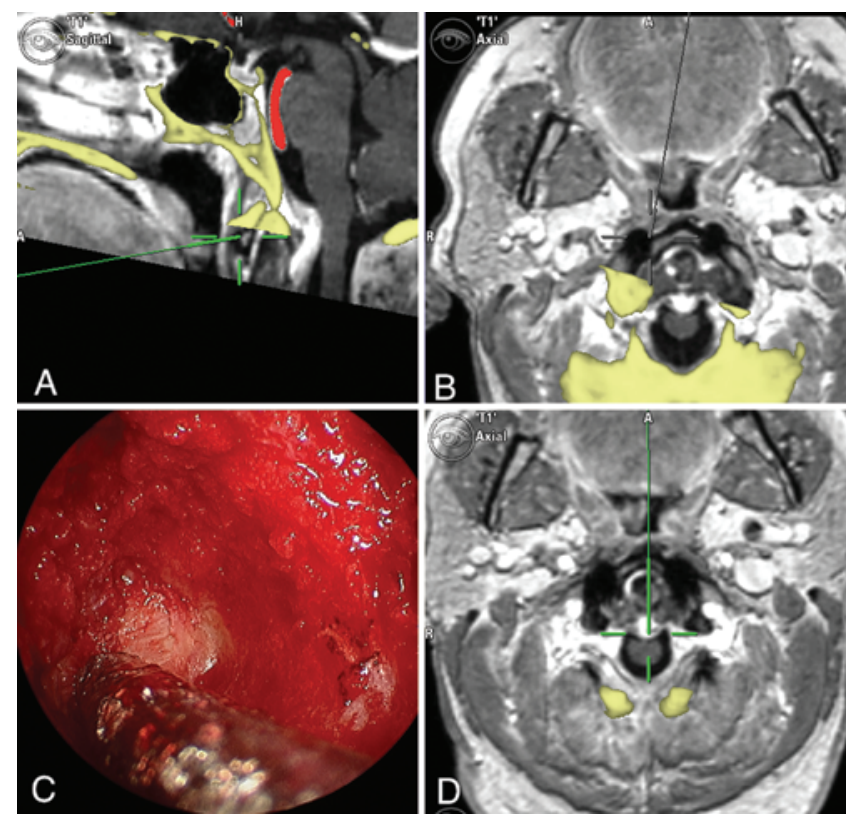

FIG. 6. A and B: Neuronavigation confirms isolation of the C-1 arch prior to skeletonization $(A)$ and adequate lateral extent of the removal of the $\mathrm{C}-1$ arch to expose the shoulders of the odontoid process (B). C: The dissection is carried through safely until exposure of the horizontal fibers of the transverse ligament. D: Neuronavigation confirms the intended decompression of the dens and soft-tissue pannus. extent of the resection of the $\mathrm{C}-1$ arch. Neuronavigation was used to ensure normal vertebral artery anatomy in the foramen transversarium of C-1 and C-2.

We then used the drill to remove the dens and the superior aspect of the C-2 vertebral body in a "top-down" method. ${ }^{31}$ This method entails the primary detachment of the apical and alar ligaments at the superior aspect of the odontoid with an angled curette or Kerrison rongeur. This method assures that the ligaments do not act as a tether, preventing the removal of the odontoid tip as in a "bottomup" approach.

The odontoid process was removed using the eggshell drilling technique while maintaining visualization with an endoscope (Video 1).

This dissection was continued dorsally until the transverse fibers of the transverse ligament were identified (Fig. $6 C)$.

The transverse ligament was dissected from the underlying pannus using a combination of a blunt nerve hook and a Kerrison punch. The pannus was then visualized. The goal of the decompression was to biopsy the lesion and debulk it. Several studies show that spontaneous resorption of the pannus is possible after posterior spinal instrumented fusion alone, so complete pannus removal is usually not needed..$^{17,45}$

Once an adequate decompression was achieved, we confirmed there were no remaining portions of the dens using neuronavigation (Fig. 6D). We used the endoscope to visualize superiorly toward the clivus.

Tissue from the pannus was sent for pathological analysis and demonstrated pseudogout (calcium pyrophosphate deposition disease).

Hemostasis was achieved using bipolar cautery. The wound was closed in layers (deep layer muscles of the longus and mucosa) using 3-0 Vicryl.

\section{Discussion}

This study demonstrates that the endoscopic transoral approach reliably accesses the CVJ. In all 10 cadaveric specimens, a comfortable working corridor was established around the CVJ, allowing for simulated odontoidectomy. In fact, the applicability of the endoscopic transoral approach may be wider than previously reported. ${ }^{3}$

Burke et al. ${ }^{3}$ suggest that the approach may be used in isolation for lesions greater than $1 \mathrm{~cm}$ below the palatal line. Furthermore, they suggest that a combined endoscopic transoral/transnasal approach may be used for lesions up to $1 \mathrm{~cm}$ above the palatal line. In our study, we find that the approach affords visualization up to $2 \mathrm{~cm}$ above the palatal line. Though it is not clear that we have control to operate at that height, we should be able to operate comfortably below it (i.e., around $1 \mathrm{~cm}$ above the palatal line). Higher lesions may be accessible, but may require augmentation with a transnasal approach. As the oral approach avoids significant morbidity, it may be the preferred approach for lesions centered about the CVJ.

This minimum superior visualization in our study also lends support to the endoscopic approach classification system proposed by the El-Sayed Staging System. ${ }^{3}$ To aid in surgical endoscopic approach selection, El-Sayed 
et al. introduced a staging system involving radiographic measurements of the $\mathrm{CVJ}$ as referenced to the palatal line, which is a line drawn along the floor of the nasal cavity extending through the premaxilla parallel to the hard palate at the CVJ. ${ }^{3,12}$ In their study, it is suggested that surgical targets lying more than $1 \mathrm{~cm}$ above the palatal line should be treated using the endoscopic transnasal approach alone. Lesions lying between $1 \mathrm{~cm}$ above and $1 \mathrm{~cm}$ below the palatal line should use the combined endoscopic transna$\mathrm{sal} /$ transoral approach. Lesions more than $1 \mathrm{~cm}$ below the palatal line should use the endoscopic transoral approach alone (Table 2). In other words, according to the El-Sayed Staging System, the endoscopic transoral approach should not be used only in the instance that the CVJ lesion is located more than $1 \mathrm{~cm}$ above the palatal line. Still, the validity of this staging system has not been well studied.

In our study, the support for the system is 2-fold. First, the superior visualization was a mean $2 \mathrm{~cm}$ above the palatal line from the transoral approach. This should afford the passage of surgical instruments below that level (namely, at $1 \mathrm{~cm}$ above the palatal line as described by the El-Sayed Staging System). Second, it appears that it is uncommon for a CVJ lesion to be located more than $1 \mathrm{~cm}$ above the palatal line. Taken together, the endoscopic transoral approach may be able to reach the majority of lesions centered at the CVJ.

It is true that there is a wide distribution of CVJ locations relative to the palatal line. As demonstrated in our study, the range of the odontoid tip, C-1 arch, and clivus, relative to the palatal line, spanned $8.6 \mathrm{~mm}, 5.8 \mathrm{~mm}$, and $8.8 \mathrm{~mm}$, respectively. This is consistent with a previous study that demonstrates the wide variability in CVJ locations. In a study on the anatomical variance of the CVJ, Burke et al. demonstrated that the CVJ is a "moving target," with two-thirds of patients having a CVJ positioned below the palatal line, $56 \%$ having a CVJ within $1 \mathrm{~cm}$ of the palatal line, and only $7 \%$ having a CVJ more than 1 $\mathrm{cm}$ below the palatal line. ${ }^{3}$ Twenty-seven percent of their group had a CVJ above the palatal line, but none were greater than $1 \mathrm{~cm}$ above the palatal line. Likewise, none of our specimens demonstrated a CVJ more than $1 \mathrm{~cm}$ above the palatal line. Furthermore, as the minimum superior reach afforded by our study was $1.1 \mathrm{~cm}$ above the palatal line, the wide applicability and potential underutilization of the endoscopic transoral approach is supported.

Aside from feasibility, surgical approach selection necessitates the avoidance of morbidity. The oropharynx provides a wide surgical corridor that avoids the dissection of the endoscopic transnasal approach. In the expanded endonasal approach, the small nasal corridor necessitates septectomy and sphenoidectomy, as well as the possible exposure of the paraclival and lacerum segments of the internal carotid artery for an adequate working corridor for surgical instruments. These dissections are associated with mucus crusting and sinusitis..$^{10,39}$ In the traditional transoral approach, a palate split is required, but it associated with velopharyngeal insufficiency. ${ }^{7,21,35,40}$ Still, other modifications involve mandibulotomy with or without glossotomy in order to reach down to C-3. The endoscopic transoral approach avoids these dissections and is associated with low morbidity.
TABLE 2. El-Sayed Staging System for endoscopic approach selection to CVJ pathology*

\begin{tabular}{cll}
\hline Type & Anatomical Location & Operative Approach \\
\hline A & $>1 \mathrm{~cm}$ above the $\mathrm{PL}$ & Endoscopic transnasal \\
\hline B & w/in $1 \mathrm{~cm}$ of the $\mathrm{PL}$ & Endoscopic oronasal \\
\hline C & $>1 \mathrm{~cm}$ below the PL & Endoscopic transoral \\
\hline $\mathrm{PL}=$ palatal line. & \\
${ }^{*}$ Based on the system in the study by Burke et al.
\end{tabular}

Despite the advantages described, the endoscopic transoral approach is not appropriate for all patients. Patients with smaller oral cavities may not have a corridor sufficient in size to accommodate the passing of instrumentation or the oral retractor system. We have found that collaboration with otolaryngologists is helpful for exposure and closure of the endoscopic transoral procedures. Centers without available otolaryngologists may have more difficulty with the approach, especially during the adoption of the technique (i.e., the learning curve). Lastly, although not presented here, there are patients with lesions that may be located very high above the palatal line (i.e., $>1 \mathrm{~cm}$ ) or very low below the palatal line. For these lesions, the expanded endonasal approach and endoscopic transcervi$\mathrm{cal}^{9,41}$ approaches may be more appropriate. It remains important to realize that a variety of CVJ lesions, such as the rheumatoid pannus presented here, are not directly localized to the odontoid tip. CVJ lesions that involve a greater portion of cephalad structures above, or pathology that results in elevation of the CVJ (e.g., platybasia ${ }^{12}$ ), may not be approachable by the endoscopic transoral approach alone.

Several limitations of the study exist. First, the cadaveric specimens were fixed, limiting mobility of the mandible. In a patient, the mandible would not only be more mobile, but neuromuscular blockade can be used to further open the jaw, thereby enhancing the reach afforded by the endoscopic transoral approach. As such, the present measurement-namely, the $2-\mathrm{cm}$ superior visualization of the approach above the palatal line-may underestimate superior access. In other words, the extent of visualization of the approach may be even greater than stated here, allowing for even higher CVJ pathologies to be reached by the endoscopic transoral approach. On the other hand, the measurements were conducted by a neuronavigational probe tip. This may not approximate the surgical freedom and surgical window area necessary for the utilization of surgical instruments, such as the drill, during odontoidectomy.

\section{Conclusions}

The endoscopic transoral approach can reliably access the CVJ. This approach avoids the dissection and morbidity associated with a palate-splitting technique (velopharyngeal insufficiency) and an expanded endonasal approach (mucus crusting, sinusitis, and potential lacerum or cavernous-paraclival internal carotid artery injury). For appropriately selected lesions near the palatal line, the endoscopic transoral approach appears to be the preferred approach. 


\section{References}

1. Apuzzo ML, Weiss MH, Heiden JS: Transoral exposure of the atlantoaxial region. Neurosurgery 3:201-207, 1978

2. Benet A, Rincon-Torroella J, Lawton MT, González Sánchez JJ: Novel embalming solution for neurosurgical simulation in cadavers. J Neurosurg 120:1229-1237, 2014

3. Burke K, Benet A, Aghi MK, El-Sayed I: Impact of platybasia and anatomic variance on surgical approaches to the craniovertebral junction. Laryngoscope 124:1760-1766, 2014

4. Burns TC, Mindea SA, Pendharkar AV, Lapustea NB, Irime I, Nayak JV: Endoscopic transnasal approach for urgent decompression of the craniocervical junction in acute skull base osteomyelitis. J Neurol Surg Rep 76:e37-e42, 2015

5. Choi D, Crockard HA: Evolution of transoral surgery: three decades of change in patients, pathologies, and indications. Neurosurgery 73:296-304, 2013

6. Choudhri O, Mindea SA, Feroze A, Soudry E, Chang SD, Nayak JV: Experience with intraoperative navigation and imaging during endoscopic transnasal spinal approaches to the foramen magnum and odontoid. Neurosurg Focus 36(3):E4, 2014

7. Crockard HA: The transoral approach to the base of the brain and upper cervical cord. Ann R Coll Surg Engl 67:321-325, 1985

8. Crockard HA, Pozo JL, Ransford AO, Stevens JM, Kendall BE, Essigman WK: Transoral decompression and posterior fusion for rheumatoid atlanto-axial subluxation. J Bone Joint Surg Br 68:350-356, 1986

9. Dasenbrock HH, Clarke MJ, Bydon A, Sciubba DM, Witham TF, Gokaslan ZL, et al: Endoscopic image-guided transcervical odontoidectomy: outcomes of 15 patients with basilar invagination. Neurosurgery 70:351-360, 2012

10. de Almeida JR, Snyderman CH, Gardner PA, Carrau RL, Vescan AD: Nasal morbidity following endoscopic skull base surgery: a prospective cohort study. Head Neck 33:547-551, 2011

11. El-Sayed IH, Wu JC, Ames CP, Balamurali G, Mummaneni PV: Combined transnasal and transoral endoscopic approaches to the craniovertebral junction. J Craniovertebr Junction Spine 1:44-48, 2010

12. El-Sayed IH, Wu JC, Dhillon N, Ames CP, Mummaneni P: The importance of platybasia and the palatine line in patient selection for endonasal surgery of the craniocervical junction: a radiographic study of 12 patients. World Neurosurg 76:183-188, 74-78, 2011

13. Fraser JF, Anand VK, Schwartz TH: Endoscopic biopsy sampling of tophaceous gout of the odontoid process. Case report and review of the literature. J Neurosurg Spine 7:61-64, 2007

14. Gempt J, Lehmberg J, Grams AE, Berends L, Meyer B, Stoffel M: Endoscopic transnasal resection of the odontoid: case series and clinical course. Eur Spine J 20:661-666, 2011

15. Goel A, Bhatjiwale M, Desai K: Basilar invagination: a study based on 190 surgically treated patients. J Neurosurg 88:962-968, 1998

16. Goldschlager T, Härtl R, Greenfield JP, Anand VK, Schwartz TH: The endoscopic endonasal approach to the odontoid and its impact on early extubation and feeding. J Neurosurg 122:511-518, 2015

17. Grob D, Würsch R, Grauer W, Sturzenegger J, Dvorak J: Atlantoaxial fusion and retrodental pannus in rheumatoid arthritis. Spine (Phila Pa 1976) 22:1580-1584, 1997

18. Hadley MN, Spetzler RF, Sonntag VK: The transoral approach to the superior cervical spine. A review of 53 cases of extradural cervicomedullary compression. J Neurosurg 71:16-23, 1989

19. Hankinson TC, Grunstein E, Gardner P, Spinks TJ, Anderson RC: Transnasal odontoid resection followed by posterior decompression and occipitocervical fusion in children with
Chiari malformation Type I and ventral brainstem compression. J Neurosurg Pediatr 5:549-553, 2010

20. Iacoangeli M, Gladi M, Alvaro L, Di Rienzo A, Specchia N, Scerrati M: Endoscopic endonasal odontoidectomy with anterior $\mathrm{C} 1$ arch preservation in elderly patients affected by rheumatoid arthritis. Spine J 13:542-548, 2013

21. Jain VK, Behari S, Banerji D, Bhargava V, Chhabra DK: Transoral decompression for craniovertebral osseous anomalies: perioperative management dilemmas. Neurol India 47:188-195, 1999

22. Kassam AB, Snyderman C, Gardner P, Carrau R, Spiro R: The expanded endonasal approach: a fully endoscopic transnasal approach and resection of the odontoid process: technical case report. Neurosurgery 57 (1 Suppl):E213, 2005

23. Komotar RJ, Starke RM, Raper DM, Anand VK, Schwartz $\mathrm{TH}$ : Endoscopic endonasal versus open transcranial resection of anterior midline skull base meningiomas. World Neurosurg 77:713-724, 2012

24. Laufer I, Greenfield JP, Anand VK, Härtl R, Schwartz TH: Endonasal endoscopic resection of the odontoid process in a nonachondroplastic dwarf with juvenile rheumatoid arthritis: feasibility of the approach and utility of the intraoperative Iso-C three-dimensional navigation. Case report. J Neurosurg Spine 8:376-380, 2008

25. Leng LZ, Anand VK, Hartl R, Schwartz TH: Endonasal endoscopic resection of an os odontoideum to decompress the cervicomedullary junction: a minimal access surgical technique. Spine (Phila Pa 1976) 34:E139-E143, 2009

26. Liu JK, Couldwell WT, Apfelbaum RI: Transoral approach and extended modifications for lesions of the ventral foramen magnum and craniovertebral junction. Skull Base 18:151166,2008

27. Liu JK, Patel J, Goldstein IM, Eloy JA: Endoscopic endonasal transclival transodontoid approach for ventral decompression of the craniovertebral junction: operative technique and nuances. Neurosurg Focus 38(4):E17, 2015

28. Menezes AH: Surgical approaches: postoperative care and complications "transoral-transpalatopharyngeal approach to the craniocervical junction". Childs Nerv Syst 24:1187-1193, 2008

29. Menezes AH, VanGilder JC: Transoral-transpharyngeal approach to the anterior craniocervical junction. Ten-year experience with 72 patients. J Neurosurg 69:895-903, 1988

30. Menezes AH, VanGilder JC, Clark CR, el-Khoury G: Odontoid upward migration in rheumatoid arthritis. An analysis of 45 patients with "cranial settling". J Neurosurg 63:500-509, 1985

31. Mummaneni PV, Haid RW: Transoral odontoidectomy. Neurosurgery 56:1045-1050, 2005

32. Nayak JV, Gardner PA, Vescan AD, Carrau RL, Kassam AB, Snyderman CH: Experience with the expanded endonasal approach for resection of the odontoid process in rheumatoid disease. Am J Rhinol 21:601-606, 2007

33. Patel AJ, Boatey J, Muns J, Bollo RJ, Whitehead WE, Giannoni CM, et al: Endoscopic endonasal odontoidectomy in a child with chronic type 3 atlantoaxial rotatory fixation: case report and literature review. Childs Nerv Syst 28:1971-1975, 2012

34. Pillai P, Baig MN, Karas CS, Ammirati M: Endoscopic image-guided transoral approach to the craniovertebral junction: an anatomic study comparing surgical exposure and surgical freedom obtained with the endoscope and the operating microscope. Neurosurgery 64 (5 Suppl 2):437-444, 2009

35. Ponce-Gómez JA, Ortega-Porcayo LA, Soriano-Barón HE, Sotomayor-González A, Arriada-Mendicoa N, GómezAmador JL, et al: Evolution from microscopic transoral to endoscopic endonasal odontoidectomy. Neurosurg Focus 37(4):E15, 2014 
36. Qiuhang Z, Feng K, Bo Y, Hongchuan G, Mingchu L, Ge C, et al: Transoral endoscopic odontoidectomy to decompress the cervicomedullary junction. Spine 38:E901-E906, 2013

37. Seker A, Inoue K, Osawa S, Akakin A, Kilic T, Rhoton AL Jr: Comparison of endoscopic transnasal and transoral approaches to the craniovertebral junction. World Neurosurg 74:583-602, 2010

38. Spetzler RF, Hadley MN, Sonntag VK: The transoral approach to the anterior superior cervical spine. A review of 29 cases. Acta Neurochir Suppl (Wien) 43:69-74, 1988

39. Starke RM, Raper DM, Payne SC, Vance ML, Oldfield EH, Jane JA Jr: Endoscopic vs microsurgical transsphenoidal surgery for acromegaly: outcomes in a concurrent series of patients using modern criteria for remission. J Clin Endocrinol Metab 98:3190-3198, 2013

40. Tuite GF, Veres R, Crockard HA, Sell D: Pediatric transoral surgery: indications, complications, and long-term outcome. J Neurosurg 84:573-583, 1996

41. Wolinsky JP, Sciubba DM, Suk I, Gokaslan ZL: Endoscopic image-guided odontoidectomy for decompression of basilar invagination via a standard anterior cervical approach. Technical note. J Neurosurg Spine 6:184-191, 2007

42. Yen YS, Chang PY, Huang WC, Wu JC, Liang ML, Tu TH, et al: Endoscopic transnasal odontoidectomy without resection of nasal turbinates: clinical outcomes of 13 patients. J Neurosurg Spine 21:929-937, 2014

43. Yu Y, Hu F, Zhang X, Ge J, Sun C: Endoscopic transnasal odontoidectomy combined with posterior reduction to treat basilar invagination: technical note. J Neurosurg Spine 19:637-643, 2013

44. Yu Y, Wang X, Zhang X, Hu F, Gu Y, Xie T, et al: Endoscopic transnasal odontoidectomy to treat basilar invagination with congenital osseous malformations. Eur Spine J 22:1127-1136, 2013

45. Zygmunt S, Säveland H, Brattström H, Ljunggren B, Larsson EM, Wollheim F: Reduction of rheumatoid periodontoid pannus following posterior occipito-cervical fusion visualised by magnetic resonance imaging. Br J Neurosurg 2:315-320, 1988

\section{Disclosures}

The authors report the following: Dr. El-Sayed serves as an educational consultant for a Stryker skull base course. Dr. Mummaneni receives royalties from DePuy Spine, Taylor and Francis/QMP Publishing, Springer Publishing Company, and Thieme Publishers; receives honoraria from Globus, DePuy, and AOSpine; has overseen support of non-study-related clinical or research effort from AANS/CNS Joint Section on Disorders of the Spine and Peripheral Nerves; and has direct stock ownership in Spinicity/ISD.

\section{Author Contributions}

Conception and design: Chan, Benet, El-Sayed, Mummaneni. Acquisition of data: all authors. Analysis and interpretation of data: Chan, Benet, Ohya, Zhang. Drafting the article: Chan, Benet, Ohya, Vogel, Flis, El-Sayed, Mummaneni. Critically revising the article: Chan, Benet, Vogel, Flis, El-Sayed, Mummaneni. Reviewed submitted version of manuscript: all authors. Approved the final version of the manuscript on behalf of all authors: Chan. Statistical analysis: Chan. Administrative/techni$\mathrm{cal} / \mathrm{material}$ support: El-Sayed, Mummaneni. Study supervision: El-Sayed, Mummaneni.

\section{Supplemental Information \\ Videos \\ Video 1. https://vimeo.com/148100928.}

\section{Correspondence}

Andrew K. Chan, Department of Neurological Surgery, University of California, San Francisco, 505 Parnassus Ave., M779, San Francisco, CA 94143. email: andrew.chan@ucsf.edu. 